\title{
Case Report \\ Dexmedetomidine Use in the Setting of Cocaine-Induced Hypertensive Emergency and Aortic Dissection: A Novel Indication
}

\author{
Fahad Javed, Alexandre Miguel Benjo, Kiran Reddy, \\ Muhammad Shoaib Akram, Shahzeb Afsar Khan, Manpreet Singh Sabharwal, \\ Girish Nadkarni, Emad F. Aziz, and Eyal Herzog
}

Division of Cardiology, St. Luke's Roosevelt Hospital Center, University Hospital for College of Physicians and Surgeons of Columbia University, 1090 Amsterdam Avenue, New York, NY 10025, USA

Correspondence should be addressed to Fahad Javed, drfahadjaved@yahoo.com

Received 1 September 2010; Revised 17 May 2011; Accepted 14 June 2011

Academic Editor: Jagdish Butany

Copyright (C) 2011 Fahad Javed et al. This is an open access article distributed under the Creative Commons Attribution License, which permits unrestricted use, distribution, and reproduction in any medium, provided the original work is properly cited.

\begin{abstract}
Aortic dissection is a potentially fatal but rare disease characterized by an aortic intimal tear with blood passing into the media creating a false lumen and with resultant high mortality depending on the location of dissection if not aggressively treated. Cocaine users are known to have a higher incidence of aortic dissection. We report here aortic dissection in a patient with cocaine abuse which did not respond to traditional medication regimes used currently in this setting. Worth mentioning is the use of an alpha2 receptor selective agonist named Dexmedetomidine as a treatment modality to control hypertension in this patient, which is approved only for sedation of intubated and mechanically ventilated patients in the intensive care settings and for sedation during invasive procedures. This paper illustrates the practical beneficial role of Dexmedetomidine in controling blood pressure in the settings of cocaine-induced sympathetic surge when other treatment modalities fail.
\end{abstract}

\section{Introduction}

Aortic dissection is a potentially fatal but rare disease characterized by an aortic intimal tear with blood passing into the media creating a false lumen. Cocaine users are known to have a higher incidence of aortic dissection [1]. Aggressive blood pressure reduction is the paradigm of aortic dissection management $[2,3]$. We present a case report of the use of dexmedetomidine, a selective alpha- 2 agonist, as an antihypertensive and sedative agent in a female with acute aortic dissection after crack cocaine who was refractory to traditional interventions.

\section{Case Report}

A 45-years-old woman brought in by EMS after she was found in distress on a subway platform. The patient with known history of diabetes type II and hypertension presented with stabbing chest pain radiating to the interscapular region after crack cocaine use. In addition to the chest pain and diaphoresis, the patient also complained of progressive pain and cold sensation over left lower extremity. Upon physical examination, the patient was noted to be agitated and combative with a blood pressure (BP) of 205/147 $\mathrm{mmHg}$, a heart rate of 77 beats per minute, 17 respirations per minute, and was afebrile. Initial cardiovascular exam was positive for an S4 gallop and absent left lower extremity pulses. Lung examination was unremarkable. Initial management consisted of intravenous administration of a total of $9 \mathrm{mg}$ of Lorazepam and $35 \mathrm{mg}$ of Labetalol without acceptable reduction in BP. In addition to further Lorazepam, Labetolol later Esmololol infusions, IV Nitroglycerin was started and quickly titrated to $200 \mathrm{mcg} / \mathrm{kg} / \mathrm{hr}$ but acceptable blood pressure reduction of blood pressure was still not achieved on this regimen (Table 1). A contrast-enhanced Computerized Tomography (CECT) of the thorax, abdomen, and pelvis 
TABLE 1

\begin{tabular}{lccccccc}
\hline Time PM & BP mm Hg & $\begin{array}{c}\text { Nitroglycerine } \\
\mathrm{mcg} / \mathrm{kg} / \mathrm{hr}\end{array}$ & $\begin{array}{c}\text { Esmolol } \\
\mathrm{mcg} / \mathrm{kg} / \mathrm{hr}\end{array}$ & Lorazepam & $\begin{array}{c}\text { Labetalol } \\
\mathrm{mg} / \mathrm{hr}\end{array}$ & $\begin{array}{c}\text { Dexmedetomidine } \\
\mathrm{mcg} / \mathrm{kg} / \mathrm{hr}\end{array}$ & Sedation level \\
\hline $3: 15$ & $214 / 129$ & 100 & 230 & $2 \mathrm{mg}$ IVP & - & - & 0 \\
$3: 25$ & & 100 & 230 & $2 \mathrm{mg}$ IVP & - & - & - \\
$3: 30$ & $215 / 120$ & 100 & 230 & $2 \mathrm{mg} \mathrm{IVP}$ & - & - & 0 \\
$3: 35$ & & 100 & 230 & $2 \mathrm{mg} / \mathrm{hr}$ & - & - & 0 \\
$3: 45$ & $194 / 120$ & 100 & 230 & $2 \mathrm{mg} / \mathrm{hr}$ & 30 & - & 0 \\
$4: 00$ & $184 / 109$ & 200 & Off & $4 \mathrm{mg} / \mathrm{hr}$ & 60 & 60 mcg bolus & $1-2$ \\
$4: 15$ & $164 / 94$ & 200 & Off & $4 \mathrm{mg} / \mathrm{hr}$ & 60 & 0.1 & $1-2$ \\
$4: 30$ & $109 / 52$ & Off & Off & $4 \mathrm{mg} / \mathrm{hr}$ & Off & 0.1 & $1-2$ \\
$4: 45$ & $118 / 70$ & Off & Off & Off & Off & 0.1 & $1-2$ \\
$5: 00$ & $121 / 70$ & Off & Off & Off & Off & 0.1 & $1-2$ \\
$5: 15$ & $123 / 71$ & Off & Off & Off & Off & 0.1 & $1-2$ \\
$5: 30$ & $132 / 78$ & Off & Off & Off & Off & & -1 \\
\hline
\end{tabular}

confirmed a Stanford Type B aortic dissection beginning just beyond the left subclavian artery and extending to the iliac bifurcation. Upon arrival to the Cardiac Care Unit, decision was made to begin an infusion of Dexmedetomidine since all other therapies continued to be unsuccessful. The alpha 2 stimulation provided by the Dexmedetomidine was hypothesized to decrease the effects of the adrenergic surge induced by the cocaine thus mitigating alpha 1 and beta-receptor stimulation. Within 10 minutes of Dexmedetomidine bolus and continuous infusion, adjunct antihypertensive and sedative infusions were quickly weaned off. Evolving signs of ischemia in the left lower extremity warranted emergent femoral-femoral bypass. Vascular surgery team performed procedure successfully and uneventfully. Postoperatively BP control was maintained with Dexmedetomidine and Nitroglycerin then Nicardipine uneventfully. The total duration of Dexmedetomidine therapy was 42 hours. The patient was transitioned to oral antihypertensives simultaneously. The clinical course evolved without any further complications, and the patient was discharged after 14 days.

\section{Discussion}

Acute aortic dissection is a life-threatening disease with estimated incidence of 2.6 to 3.5 per 100,000 person-years [46]. The incidence is higher in certain populations including patients suffering from Marfan's syndrome and cocaine users [7]. Crack cocaine abuse accounts for up to 37 percent of dissections amongst select populations $[8,9]$. Inhibition of norepinephrine reuptake by cocaine within peripheral sympathetic nerve synaptic clefts leads to a sympathetic surge within cutaneous and skeletal muscle beds [10-15]. The end result is an increase in peripheral vasoconstriction and tachycardia, which causes an increase in aortic shearing forces and in turn increases the risk for intimal rupture.

Intuitively, reduction of aortic shearing forces is a basic tenet of acute aortic dissection management. The stimulation of alpha-2 adrenergic receptors by Dexmedetomidine and
Clonidine in the medullary vasomotor center reduces Norepinephrine turnover thus decreasing central sympathetic outflow. These pharmacologic interventions also increase parasympathetic outflow and inhibit sympathetic outflow from the locus coerulous which allows for increased stimulation of inhibitory neurons including the gamma amino butyric acid (GABA) system. GABA promotes sedation and analgesia, decreases minimum alveolar concentration of inhalational anesthetic needs, blunts sympathetic nervous response to noxious stimuli, and decreases blood pressure and heart rate [16-19]. Dexmedetomidine is FDA approved for sedation of intubated and mechanically ventilated patients in the intensive care setting and for sedation during invasive procedures. Recently, there have been several cases of "off label" use of Dexmedetomidine for patients who were found to fail traditional weaning procedures as the sedative effects of Dexmedetomidine have the benefit of not suppressing respiratory drive. Clonidine, another alpha-2 receptor agonist, and in some case reports Dexmedetomidine have been explored for cocaine and opiate withdrawal and detoxification [19-30]. There are also some experimental data demonstrating Clonidine's effect in blunting cocaineinduced hypertension [31]. In the same manner, there is one study that demonstrated that concomitant administration of Dexmedetomidine along with cocaine to healthy volunteers blunted its sympathomimetic effects; however, our search of the literature did not yield any reports of the clinical application of Dexmedetomidine specifically for cocaine-induced hypertension or even hypertension itself.

Compared to Clonidine, Dexmedetomidine has multiple advantages. Dexmedetomidine is 8 times more alpha- 2 selective than Clonidine [32], has a shorter half-life (2-3 hours versus 12-24 hour), and is equally efficacious in Caucasians and African Americans; Clonidine has been shown to be less effective in African Americans [33]. These characteristics make Demedetomidine a suitable drug for the continuous intravenous infusion and a better alpha- 2 adrenergic agent for the treatment of cocaine-induced hypertension. Furthermore, Dexmedetomidine may even have a role in 
noncocaine-induced hypertensive urgencies and emergencies or as an overall Clonidine substitute. However, some caution is advised in using Dexmedetomidine. Though it is a selective alpha-2 agonist, in higher doses it may result in hypertension due to alpha-1 stimulation that in the usual dose range is uncommon [34] and was not observed practically in our patient.

\section{Conclusion}

In conclusion, this paper demonstrates that Dexmedetomidine can be used in cocaine-induced hypertensive aortic dissection management secondary to its dual properties of reducing blood pressure and heart rate in addition to its sedative and analgesic properties which directly address cocaineinduced anxiety and dissection-related pain that further contribute to the adrenergic surge. This paper provides a practical insight that Dexmedetomidine can be considered as a therapeutic agent to address sympathomimetic consequences of acute cocaine ingestion and related hypertensive crisis, and possible other hypertensive situations though data is limited to date and needs further exploration.

\section{Consent}

Informed written consent was received for publication of the paper and figures by hospital authorities for academic purposes after ensuring HIPPA regulation as per New York Patient Bill of Rights. Copy of HIPPA form can be provided upon request.

\section{Conflict Of Interests}

The authors declare no conflict of interests.

\section{References}

[1] P. Y. Hsue, C. L. Salinas, A. F. Bolger, N. L. Benowitz, and D. D. Waters, "Acute aortic dissection related to crack cocaine," Circulation, vol. 105, no. 13, pp. 1592-1595, 2002.

[2] R. Erbel, F. Alfonso, C. Boileau et al., "Diagnosis and management of aortic dissection," European Heart Journal, vol. 22, no. 18, pp. 1642-1681, 2001.

[3] T. T. Tsai, C. A. Nienaber, and K. A. Eagle, "Acute aortic syndromes," Circulation, vol. 112, no. 24, pp. 3802-3813, 2005.

[4] L. K. Bickerstaff, P. C. Pairolero, and L. H. Hollier, "Thoracic aortic aneurysms: a population-based study," Surgery, vol. 92, no. 6, pp. 1103-1108, 1982.

[5] I. Meszaros, J. Morocz, J. Szlavi et al., "Epidemiology and clinicopathology of aortic dissection," Chest, vol. 117, no. 5, pp. 1271-1278, 2000.

[6] W. D. Clouse, J. W. Hallett Jr., H. V. Schaff et al., "Acute aortic dissection: population-based incidence compared with degenerative aortic aneurysm rupture," Mayo Clinic Proceedings, vol. 79, no. 2, pp. 176-180, 2004.

[7] J. L. AU Januzzi, E. M. Isselbacher, R. Fattori et al., "Characterizing the young patient with aortic dissection: results from the international registry of aortic dissection (IRAD)," Journal of the American College of Cardiology, vol. 43, no. 4, pp. 665-669, 2004.
[8] J. C. Daniel, T. T. Huynh, W. Zhou et al., "Acute aortic dissection associated with use of cocaine," Journal of Vascular Surgery, vol. 46, no. 3, pp. 427-433, 2007.

[9] K. A. Eagle, E. M. Isselbacher, and R. W. DeSanctis, "Cocainerelated aortic dissection in perspective," Circulation, vol. 105, no. 13, pp. 1529-1530, 2002.

[10] J. Axelrod, L. G. Whitby, and G. Hertting, "Effect of cocaine on the disposition of noradrenaline labelled with tritium," Nature, vol. 187, no. 4737, pp. 604-605, 1960.

[11] E. Muscholl, "Effect of cocaine and related drugs on the uptake of noradrenaline by heart and spleen," BritishJournal of Pharmacology and Chemotherapy, vol. 16, pp. 352-359, 1961.

[12] R. F. Furchgott, S. M. Kirpeker, M. Rieker, and A. Schwab, "Action and interactions of norepinephrine, tyramine, and cocaine on aortic strips of rabbit and left atria guinea pig and cat," Journal of Pharmacology, vol. 142, pp. 39-58, 1963.

[13] J. H. Jaffe, "Drug addiction and drug abuse," in The Pharmacologic Basis of Therapeutics, A. G. Gilman, T. W. Rall, A. S. Nies, and P. Taylor, Eds., pp. 539-546, Pergamon Press, New York, NY, USA, 1990.

[14] R. A. Gillis, Y. M. Hernandez, H. K. Erzouki et al., "Sympathetic nervous system mediated cardiovascular effects of cocaine are primarily due to a peripheral site of action of the drug," Drug and Alcohol Dependence, vol. 37, no. 3, pp. 217230, 1995.

[15] W. Vongpatanasin, Y. Mansour, B. Chavoshan, D. Arbique, and R. G. Victor, "Cocaine stimulates the human cardiovascular system via a central mechanism of action," Circulation, vol. 100, no. 5, pp. 497-502, 1999.

[16] P. Duke, "Dexmedetomidine: a general overview," International Congress and Symposium Series: Redefining Sedation, no. 221, pp. 11-22, 1998.

[17] R. Aantaa, J. Kanto, M. Scheinin, A. Kallio, and H. Scheinin, "Dexmedetomidine, an $\alpha_{2}$-adrenoceptor agonist, reduces anesthetic requirements for patients undergoing minor gynecologic surgery," Anesthesiology, vol. 73, no. 2, pp. 230-235, 1990.

[18] R. Aantaa, "Assessment of the sedative effects of dexmedetomidine, an $\alpha_{2}$-adrenoceptor agonist, with analysis of saccadic eye movements," Pharmacology and Toxicology, vol. 68, no. 5, pp. 394-398, 1991.

[19] K. Baddigam, P. Russo, J. Russo, and J. D. Tobias, "Dexmedetomidine in the treatment of withdrawal syndromes in cardiothoracic surgery patients," Journal of Intensive Care Medicine, vol. 20, no. 2, pp. 118-123, 2005.

[20] G. R. Baumgartner and R. C. Rowen, "Transdermal clonidine versus chlordiazepoxide in alcohol withdrawal: a randomized, controlled clinical trial," Southern Medical Journal, vol. 84, no. 3, pp. 312-321, 1991.

[21] I. Dobrydnjov, K. Axelsson, L. Berggren, J. Samarutel, and B. Holmstrom, "Intrathecal and oral clonidine as prophylaxis for postoperative alcohol withdrawal syndrome: a randomized double-blinded study," Anesthesia and Analgesia, vol. 98, no. 3 , pp. 738-744, 2004.

[22] A. H. Lichtman, J. Fisher, and B. R. Martin, "Precipitated cannabinoid withdrawal is reversed by $\triangle 9$-tetrahydrocannabinol or clonidine," Pharmacology Biochemistry and Behavior, vol. 69, no. 1-2, pp. 181-188, 2001.

[23] P. C. Yam, A. Forbes, and W. J. Kox, "Clonidine in the treatment of alcohol withdrawal in the intensive care unit," British Journal of Anaesthesia, vol. 68, no. 1, pp. 106-108, 1992.

[24] E. L. Hoder, J. F. Leckman, R. Ehrenkranz et al., "Clonidine in neonatal narcotic-abstinence syndrome," The New England Journal of Medicine, vol. 305, no. 21, p. 1284, 1981. 
[25] H. Ashton, "Benzodiazepine withdrawal: outcome in 50 patients," British Journal of Addiction, vol. 82, no. 6, pp. 665-671, 1987.

[26] American Academy of Pediatrics Committee on Drugs, "Neonatal drug withdrawal (RE9746)," Pediatrics, vol. 6, pp. 113$117,1998$.

[27] B. C. McClain, L. A. Probst, E. Pinter, and M. Hartmannsgruber, "Intravenous clonidine use in a neonate experiencing opioid-induced myoclonus," Anesthesiology, vol. 95, no. 2, pp. 549-550, 2001.

[28] G. A. Maccioli, "Dexmedetomidine to facilitate drug withdrawal," Anesthesiology, vol. 98, no. 2, pp. 575-577, 2003.

[29] A. S. Multz, "Prolonged dexmedetomidine infusion as an adjunct in treating sedation-induced withdrawal," Anesthesia and Analgesia, vol. 96, no. 4, pp. 1054-1055, 2003.

[30] J. C. Finkel and A. Elrefai, "The use of dexmedetomidine to facilitate opioid and benzodiazepine detoxification in an infant," Anesthesia and Analgesia, vol. 98, no. 6, pp. 1658-1659, 2004.

[31] W. Mo, J. A. Arruda, G. Dunea, and A. K. Singh, "Cocaineinduced hypertension: role of the peripheral sympathetic system," Pharmacological Research, vol. 40, no. 2, pp. 139-145, 1999.

[32] J. B. Dyck and S. L. Shafer, "Dexmedetomidine pharmacokinetics and pharmacodynamics," Anaesth Pharm Review, vol. 1, pp. 238-245, 1993.

[33] D. Kurnik, M. Muszkat, G. G. Sofowora et al., "Ethnic and genetic determinants of cardiovascular response to the selective $\alpha 2$-adrenoceptor agonist dexmedetomidine," Hypertension, vol. 51, no. 2, pp. 406-411, 2008.

[34] G. Erkonen, F. Lamb, and J. D. Tobias, "High-dose dexmedetomidine-induced hypertension in a child with traumatic brain injury," Neurocritical Care, vol. 9, no. 3, pp. 366-369, 2008. 


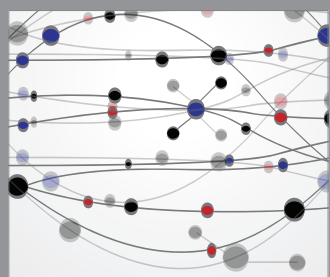

The Scientific World Journal
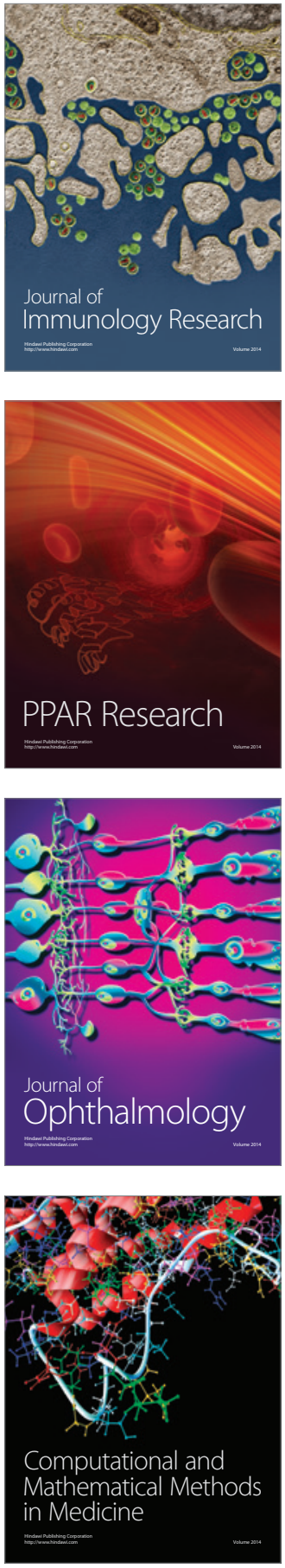

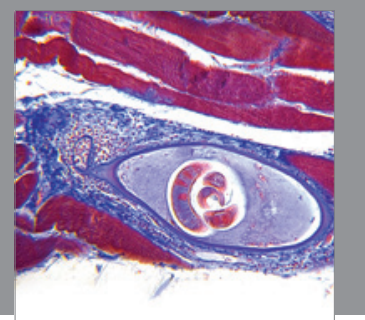

Gastroenterology

Research and Practice
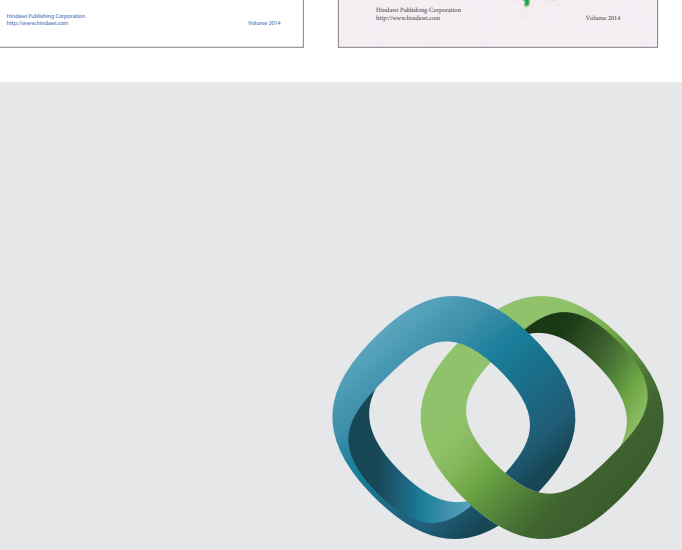

\section{Hindawi}

Submit your manuscripts at

http://www.hindawi.com
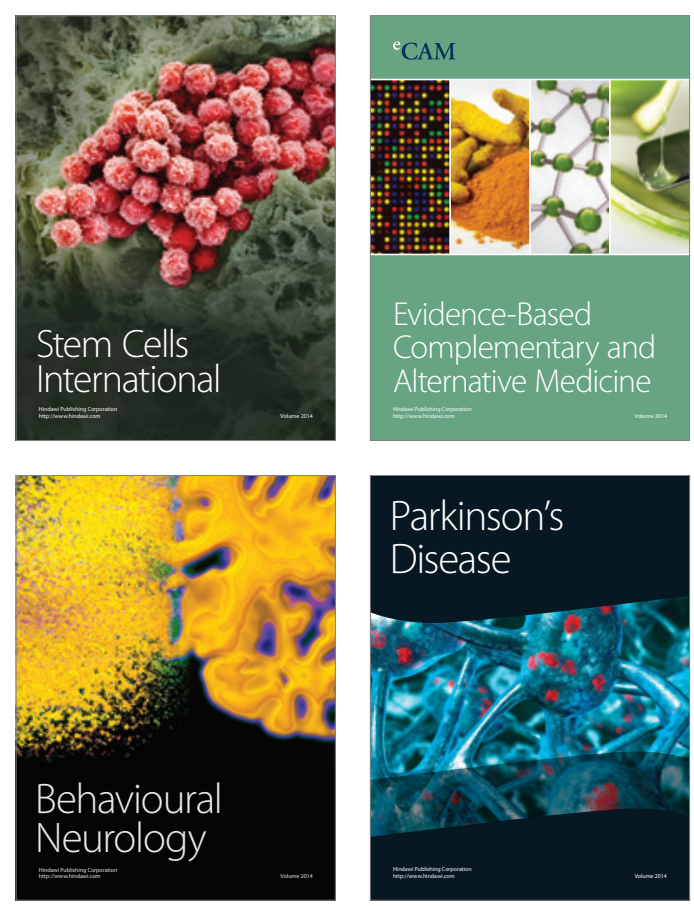

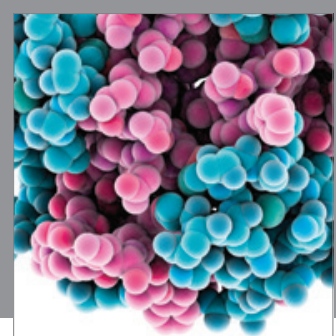

Journal of
Diabetes Research

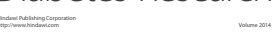

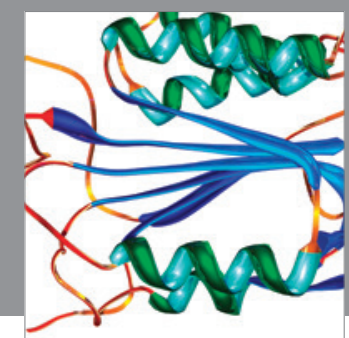

Disease Markers
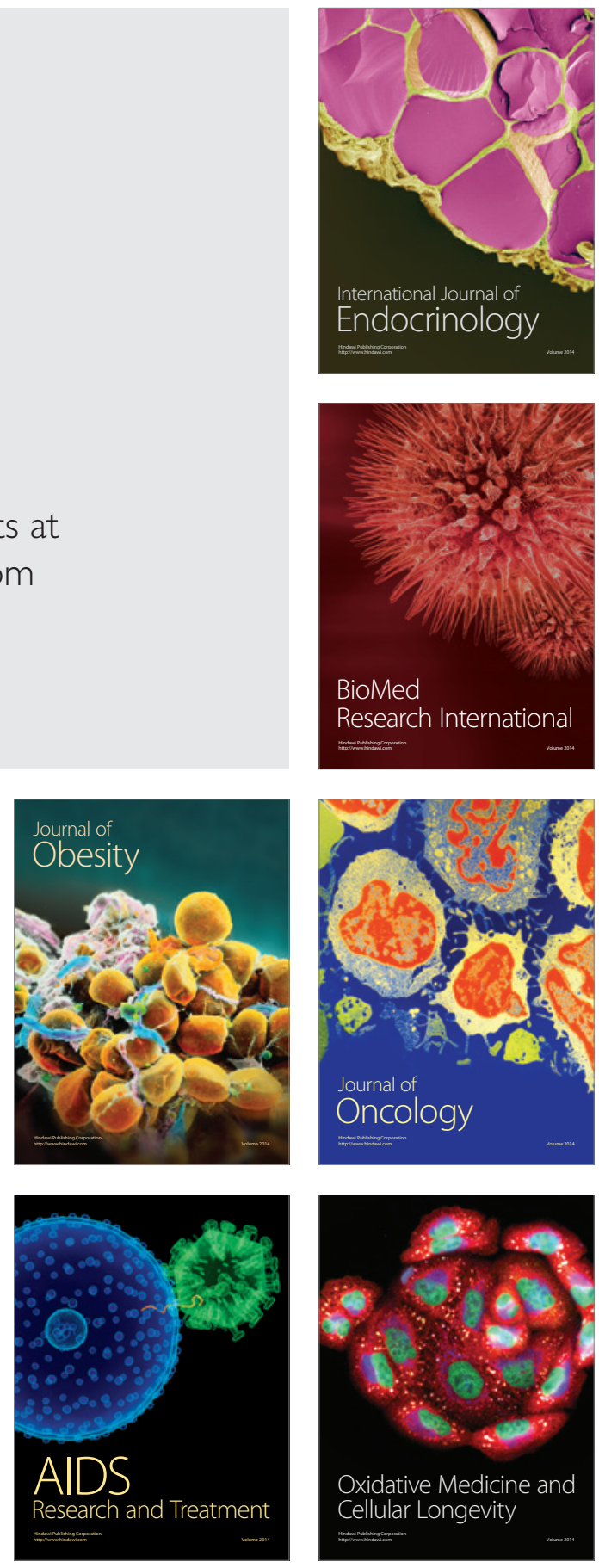